\title{
Endoscopic Resection of Xanthogranulomatous Gastritis Presenting as a Subepithelial Tumor: A Case Report
}

\author{
Tae Wan Kim, Tae Ho Kim, Chang Whan Kim, Jae Hyuck Chang, Sok Won Han, Jae Kwang Kim \\ Department of Internal Medicine, The Catholic University of Korea, Bucheon St. Mary's Hospital, Bucheon, Korea
}

\begin{abstract}
Xanthogranulomatous gastritis (XGG) presenting as a subepithelial tumor (SET) is a very rare entity. We report a case of SET-like XGG diagnosed and treated with endoscopic resection. A 55-year-old female patient was initially referred with a 1.5-cm SET located at the anterior wall of the middle antrum. Endoscopic ultrasound examination revealed submucosal invasion without any perigastric lymph node enlargement. Endoscopic resection was performed for an accurate diagnosis and treatment, and the lesion was diagnosed histopathologically as XGG. At the 18-month follow-up after endoscopic resection, there was no evidence of XGG recurrence. SET-like XGG is very rare and the diagnosis is a preoperative challenge. However, inflammatory tumors should be considered in the differential diagnosis of SET. (Korean J Helicobacter Up Gastrointest Res 2018;18:198-203)
\end{abstract}

Key Words: Endoscopic resection; Subepithelial tumor; Xanthogranulomatous gastritis

\section{INTRODUCTION}

Xanthogranuloma is found frequently in gallbladder or kidney, and is rarely reported in other organs. ${ }^{1,2}$ The presence of xanthogranuloma has been reported in stomach, colon, pancreas, and uterus. In the case of stomach, reports of xanthogranulomatous gastritis (XGG), which is a type of subepithelial tumor (SET), are available internationally. ${ }^{3-14}$ The $\mathrm{XGG}$, is misdiagnosed as an advanced gastric cancer or gastrointestinal stromal tumor (GIST), and is diagnosed after partial or total gastric resection. $^{3-6,9,11,12,14}$ The incidence or fatality rate of XGG is unknown, and no optimal treatment has been found. ${ }^{14}$ No reported diagnoses of XGG or endoscopic treatment are available in the English-language literature.

Histopathologically, xanthogranuloma is characterized by numerous fibroses, abundance of foamy cells, and Touton giant cells mixed with acute or chronic inflammatory cells. ${ }^{13}$ Although the etiology is unclear, hypotheses include lipid transport defects, immunological dysfunction, and decreased clearance after infection with low-viru-

\footnotetext{
Received: February 12, 2018 Revised: April 4, 2018 Accepted: April 6, 2018

Corresponding author: Tae Ho Kim

Department of Internal Medicine, The Catholic University of Korea, Bucheon St. Mary's Hospital, 327 Sosa-ro, Wonmi-gu, Bucheon 14647, Korea

Tel: +82-32-340-7017, Fax: +82-32-340-7227, E-mail: drkimtaeho@gmail.com

(1) ORCID: https://orcid.org/0000-0003-2015-5176
}

lence pathogens, lymphatic obstruction, and so forth. ${ }^{15}$

In Korea, XGG presenting as a SET has never been reported. To the best of our knowledge, no reports of XGG presenting as a SET treated endoscopically are available in the English-language literature. We report a case of XGG presenting as a SET that was diagnosed and treated endoscopically.

\section{CASE REPORT}

A SET was found in the stomach of a 56-year-old female during her health examination, and was referred for further examination and treatment. The patient had no gastrointestinal symptoms. The patient was diagnosed with hypertension two years ago, and has been treated with medications. The patient had no history of alcoholism or smoking. On initial diagnostic endoscopy, a protruded mass, measuring $1.5 \mathrm{~cm}$ in diameter, was found in the anterior wall of middle antrum (Fig. 1A). The lesion could not exclude epithelial lesion due to yellowish white and mild depression on mucosal surface. But, the mass was very hard and the result of biopsy indicated a hyperplastic polyp. Moreover, considering the shape and mobility of the tumor, it was thought a SET. In endoscopic ultrasonography (EUS) conducted in the outpatient clinic, the depth of invasion involved the third submucosal layer,

Copyright $\odot 2018$ Korean College of Helicobacter and Upper Gastrointestinal Research

(ङ) The Korean Journal of Helicobacter and Upper Gastrointestinal Research is an Open-Access Journal. All articles are distributed under the terms of the Creative Commons Attribution Non-Commercial License (http://creativecommons.org/licenses/by-nc/4.0) which permits unrestricted non-commercial use, distribution, and reproduction in any medium, provided the original work is properly cited. 

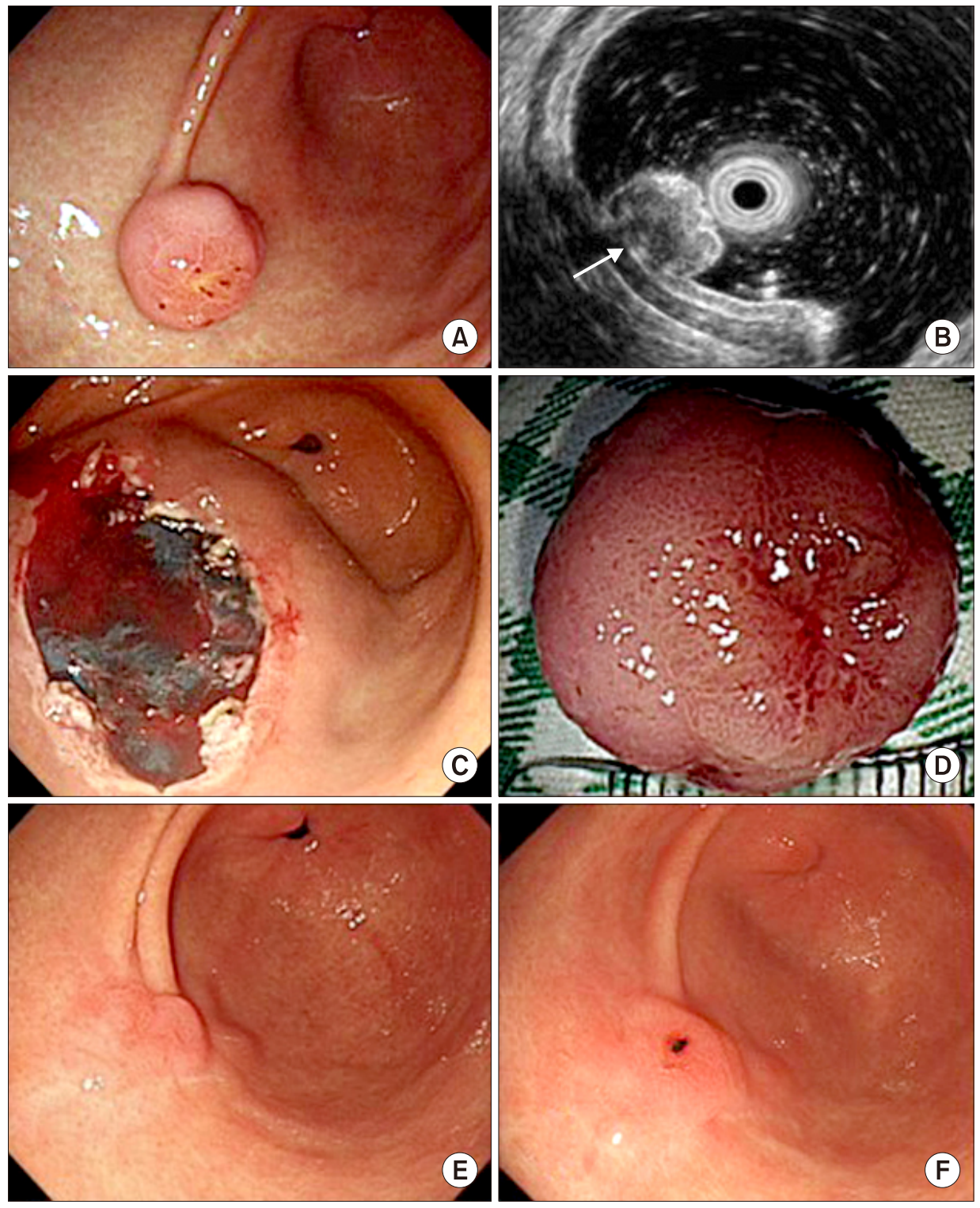

Fig. 1. (A) Initial endoscopy shows a $1.5 \mathrm{~cm}$ subepithelial tumor with small erosion and hematins at the anterior wall of the middle antrum. (B) Endoscopic ultrasonography shows a heterogenously hypoechoic mass in the deep mucosal and submucosal layer (arrow). (C) The clear resection margin without remnant tissue following endoscopic resection is shown. (D) The resected tumor measured $1.6 \times 1.4 \times 1.3 \mathrm{~cm}$. (E, F) At the 6and 18-month follow-up endoscopy, the post-endoscopic resection scar (S2) with regenerating granuloma is visible.

and no perigastric lymph node enlargement was found (Fig. 1B). Endoscopic resection was used to determine if the mass was a leiomyoma, carcinoid tumor, or malignant tumor.

At the time of the visit, the vital signs were stable: blood pressure 100/60 mmHg, heart rate 75 beats per minute, respiratory rate 20 breaths per minute, and body temperature $36.5^{\circ} \mathrm{C}$, with clear consciousness. Abdominal examination, thoracic and abdominal auscultations showed no abnormal findings. No abdominal mass or palpable lymph node was found. The results of a peripheral blood test were as follows: white blood cell count was $8,790 / \mu \mathrm{L}$, hemoglobin $13.7 \mathrm{~g} / \mathrm{dL}$, thrombocyte count 292,000/ $\mu \mathrm{L}$, calcium $9.3 \mathrm{mg} / \mathrm{dL}$, aspartate aminotransferase $17 \mathrm{IU} / \mathrm{L}$, alanine aminotransferase $20 \mathrm{IU} / \mathrm{L}, \mathrm{C}$-reactive protein $1.2 \mathrm{mg} / \mathrm{L}$, creatinine $0.77 \mathrm{mg} / \mathrm{dL}$, and blood urea nitrogen $17.5 \mathrm{mg} / \mathrm{dL}$, indicating nothing significant in particular. Since no invasion through perigastric lymph node was confirmed by the EUS, the endoscopic resection was conducted without abdominal computed tomography (CT) (Fig. 1C).

The resected tissue measured $1.6 \times 1.4 \times 1.3 \mathrm{~cm}$, with a $0.3 \mathrm{~cm}$ depressed lesion at the central portion (Fig. 1D). Hematoxylin-eosin staining revealed a mucosal and sub- 
mucosal lesion (Fig. 2A). The lesion contained numerous fibroid tissues, reticulohistiocytosis, Touton giant cells, and foamy cells, with no sign of tumor invasion in the resected cross-section (Fig. 2B).

The patient was discharged 3 days later without complications. In a follow-up endoscopy 6 months later, an ulcer scar that stemmed from the endoscopic resection was found on the anterior wall of the middle antrum (Fig. 1E). To evaluate the recurrence, a forceps biopsy was conducted. The histological finding indicated regenerative mucosa. Considering the association between xanthoma and Helicobacter pylori, a rapid urease test was performed. The rapid urease test result was positive, and a standard-dose triple therapy was performed. Urea breath test 2 months later showed successful eradication, and endoscopy was conducted one year later (Fig. 1F). Forceps biopsy of the endoscopic resection scar confirmed regenerative mucosa. The patient is currently on trace as an outpatient, without recurrence.

\section{DISCUSSION}

We compared the present case with other previously reported cases (Table 1). Seven out of 13 cases $^{3-14}$ were male, with an average age of 66 years (range, 48 86 years). The preoperative diagnosis of 5 cases was gastric cancer. $^{3-6,11}$ Another 8 cases were diagnosed as SETs, ${ }^{7-10,12-14}$ including 3 cases of suspected GIST. ${ }^{8,12,14}$ The 12 cases reported previously were all treated surgically, and only the case reported here was treated
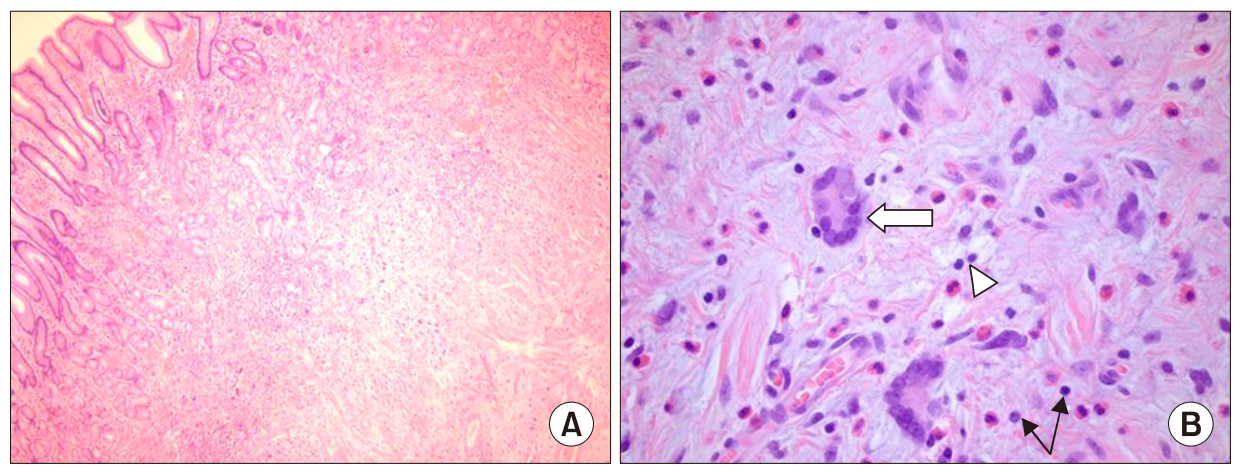

Fig. 2. Pathologic findings of the tumor. (A) Low-power view shows a subepithelial tumor located in the deep mucosa and submucosa, and lipid-laden histiocytes and fibrocyte proliferation are seen $(\mathrm{H} \& \mathrm{E}, \times 20)$. (B) High-power view of the foamy cell-rich area shows multinucleated giant cells known as Touton giant cells (arrow) and lipid-laden histiocytes (arrowhead), and numerous inflammatory cells (arrow line) $(\mathrm{H} \& \mathrm{E}, \times 400)$.

Table 1. Summary of Xanthomgranulomatous Gastritis in Previously Reported Cases and the Present One

\begin{tabular}{|c|c|c|c|c|c|c|c|}
\hline Study & Year & $\begin{array}{c}\text { Gender/age } \\
(\mathrm{yr})\end{array}$ & $\begin{array}{c}\text { Preoperative } \\
\text { diagnosis }\end{array}$ & Operation & $\begin{array}{l}\text { Comorbid } \\
\text { disease }\end{array}$ & $\begin{array}{l}\text { Helicobacter } \\
\text { pylori study }\end{array}$ & $\begin{array}{l}\text { Recur (1 year } \\
\text { after surgery) }\end{array}$ \\
\hline $\begin{array}{l}\text { Zafisaona and } \\
\text { Kermarec }^{3}\end{array}$ & 1987 & Female/67 & AGC & TG & - & ND & ND \\
\hline Zhang et al. ${ }^{4}$ & 1992 & Male/70 & AGC & PR & - & ND & ND \\
\hline Guarino et al. ${ }^{5}$ & 1993 & Male/79 & AGC & DG & XGC & ND & Free \\
\hline Lespi $^{6}$ & 1998 & Male/48 & AGC & STG & - & ND & ND \\
\hline Lai et al. ${ }^{7}$ & 2006 & Female/58 & SET & TG, S, DP & GU perforation & ND & ND \\
\hline Kubosawa et al. $^{8}$ & 2007 & Male/77 & SET (GIST) & PR & - & ND & Free \\
\hline Aikawa et al. ${ }^{9}$ & 2009 & Male/67 & SET & DG & EGC & ND & ND \\
\hline Banerjee et al. ${ }^{10}$ & 2010 & Male/51 & SET & DG & GU perforation & ND & ND \\
\hline Kinoshita et al. ${ }^{11}$ & 2011 & Female/65 & AGC & TG & EGC & ND & Free \\
\hline Tsukada et al. $^{12}$ & 2012 & Female/79 & SET (GIST) & PR & - & ND & Free \\
\hline Tajima et al. ${ }^{13}$ & 2015 & Female/86 & SET & DG & Actinomycosis & Negative & Free \\
\hline Okamura et al. ${ }^{14}$ & 2016 & Male/64 & SET (GIST) & Roux-en-Y & - & ND & Free \\
\hline Present case & 2016 & Female/55 & SET & ESD & - & Positive & Free \\
\hline
\end{tabular}

AGC, advanced gastric cancer; TG, total gastrectomy; -, none; ND, not described; PR, partial resection; DG, distal gastrectomy; XGC, xanthogranulomatous cholecystitis; STG, subtotal gastrectomy; SET, subepithelial tumor; S, splenectomy; DP, distal pancreatectomy; GU, gastric ulcer; GIST, gastrointestinal stromal tumor; EGC, early gastric cancer; ESD, endoscopic submucosal dissection. 
endoscopically. Three cases underwent total gastrectomy, ${ }^{3,7,11} 4$ cases did distal gastrectomy, ${ }^{5,9,10,13} 3$ cases did partial gastrectomy, ${ }^{4,8,12} 1$ case did subtotal gastrectomy, ${ }^{6}$ and 1 case did Roux-en-Y. ${ }^{14}$ In addition, 6 cases involved comorbidities: 2 cases of early gastric cancer (EGC), ${ }^{9,11} 2$ cases of gastric ulcer perforation, ${ }^{7,10} 1$ case of xanthogranulomatous cholecystitis (XGC), ${ }^{5}$ and 1 case of actinomycosis. ${ }^{13}$ Trace history involving 7 patients for more than 1 year showed no recurrence. ${ }^{5,8,11-14}$

The pathogenesis of xanthogranulomatous inflammation (XGI) is yet to be elucidated. XGI is a rare inflammatory response, and occurs in the gallbladder and kidney. In the case of XGC, it is hypothesized that extravasation of bile is triggered by the destruction of Rokitansky-Aschoff sinus, which then induces phagocytosis and histiocyte accumulation that eventually results in XGC. ${ }^{1}$ On the other hand, xanthogranulomatous pylelonephritis (XGP) has been attributed to urinary tract infection by Escherichia coli and obstruction. ${ }^{2}$

The pathogenesis of gastric XGI has been hypothesized to involve a continued backflow of bile infiltrating the submucosa via damaged gastric mucosa. ${ }^{1,5}$ However, the reverse flow of bile was not clearly detected in patients with XGG in the English-language literature. Another hypothesis suggested a microbial infection. However, only a single case involved infection (actinomycosis). ${ }^{13}$ While studies may associate the occurrence of xanthoma with Helicobacter infection, ${ }^{16}$ additional investigations are needed since Helicobacter test was positive in only two XGG cases including the present case. The third hypothesis associates XGG with malignant tumor. Until now, only two cases of XGG were found along with EGC.,11 Since only a few cases involved XGG, additional investigations are needed to establish its relationship with malignant tumor. Other hypotheses suggest defective lipid transport, or lymphatic closure as well as immune dysfunction. ${ }^{15}$

While the features of XGI in XGC and XGP is the invasion into the local tissue, the invasiveness of $X G G$ is not clearly known, because there are not many XGG cases. In the case of XGG, which accompanied bleeding or severe abdominal pain, were reported with the invasiveness of local tissue. ${ }^{11-14}$ However, the invasiveness of XGG in asymptomatic patients has not been reported. In addition, while previous cases confirmed the invasion of the subserosal layer through surgery, the present case did not confirm that the invasion beyond the submucosa, since endoscopic resection was performed.

The XGG with a form of SET is very difficult to diagnose prior to surgical treatment. Endoscopically, SET-like XGG is accompanied with ulcer, and CT sometimes suggests malignancy if accompanying peripheral lymph node enlargement is seen. Further, in positron emission tomography CT, the XGG showed increased fludeoxyglucose uptake, which can easily be mistaken as a gastric cancer or GIST. ${ }^{12}$ Hence, the diagnosis of most XGG patients reported in the English-literature was modified following partial or total gastrectomy. It is therefore, important to consider possible differential diagnosis of inflammatory tumors such as XGG as well as malignant tumors, when a gastric SET is found.

When hypoechoic lesions originating from the submucosal layer are observed in SET lesions, GIST, leiomyoma, carcinoid tumor, or lymphoma should be considered. GIST is usually seen as a hypoechoic oval shape lesion or lobulated pedunculated lesion originating from the 4th layer. If the diameter of the lesion is more than $3 \mathrm{~cm}$ on EUS, or when irregular margin, disruption of EUS layer, or perigastric lymph node enlargement are shown, a malignant alteration should be considered. Neuroendocrine tumors arise from the deep mucosa and invade the submucosa layer. Endoscopic findings might indicate this as a solid, superficial SET covered with normal mucosa and slightly yellowish coloration. In metastatic tumors, multiple nodules of varying size with central ulceration are found and EUS shows hypoechoic lesions in any of the above layers. ${ }^{17}$ In addition, as in this case, if erosive or ulcerative changes at the SET are accompanied and the EUS shows hypoechoic lesions originating from the deep mucosal and submucosal layer, although rare, XGG should also be considered. Endoscopic resection of these lesions has been reported to be safe if the lesion is less than 2 $\mathrm{cm}$ in diameter and does not invade the proper muscle layer.

In addition, in the case of XGG, no neovascularization or tumor staining was found in angiography, in contrast to typical malignant tumors. ${ }^{12}$ However, only a single case 
was detected using angiography.

According to a study conducted in Sweden, the prevalence of SETs in endoscopy is $0.36 \%$, while in Korea it was relatively high at $1.7 \% .^{18}$ The SETs found were GIST, leiomyoma, lipoma, carcinoid tumor, granular cell tumor, ectopic pancreas, cyst, and so forth. According to the study, the incidence increased in older females. ${ }^{18}$ The diagnosis was supported by the size, depth, and variation in SET pattern, using EUS and either bite-on-bite biopsy or deep biopsy. If the tumor is located mainly on the lamina propria, a bite-on-bite method can be adopted to obtain the SET tissue. However, there is a limitation in that the rate of successful diagnosis is only $14 \%$ to $42 \%$. GIST or leiomyoma is an indication for EUS-induced tissue biopsy, and the diagnostic accuracy is about 50 70\%. Patients with SET exceeding $2 \mathrm{~cm}$ in size can manifestate SET-related symptoms, or reveal potential for malignancy endoscopically or on EUS. The mainstay of treatment so far has been surgery. However, endoscopic resection of these lesions has been reported to be safe if the lesion is less than $2.5 \mathrm{~cm}$ in diameter and does not invade the proper muscle layer. ${ }^{19}$ And comparison of the surgical outcome with endoscopic submucosal dissection (ESD), assuming a SET size less than $4 \mathrm{~cm}$, revealed no significant differences in recurrence for the trace period longer than 30 months, although the ESD showed a lower rate of $\mathrm{R}_{0}$ resection. ${ }^{20}$ Therefore, endoscopic resection can be considered as an acceptable tool for SET diagnosis and treatment.

The present case report is the first in the world reporting the diagnosis and treatment of SET-type XGG via EUS and endoscopic resection. Although the trace period in this patient was only 18 months, which is relatively short, no recurrence has been reported to date. The prevalence of SETs in Korea is high, compared to Europe, and expected to increase in the future due to aging population. While few cases of XGG with a form of SET have been reported in the literature based on EUS-guided fine needle aspiration or deep biopsy, it is desirable to monitor the cases with endoscopic resection. Further, a diagnosis of XGG in frozen biopsy during surgical treatment should lead to a reduction in surgery to diminish the risk of postsurgical complications.

\section{REFERENCES}

1. Ladefoged C, Lorentzen M. Xanthogranulomatous cholecystitis. A clinicopathological study of 20 cases and review of the literature. APMIS 1993;101:869-875.

2. Korkes F, Favoretto RL, Bróglio M, Silva CA, Castro MG, Perez MD. Xanthogranulomatous pyelonephritis: clinical experience with 41 cases. Urology 2008;71:178-180.

3. Zafisaona G, Kermarec J. Inflammatory fibrous histiocytoma of the stomach. Apropos of a case of xanthogranuloma? Arch Anat Cytol Pathol 1987;35:149-153.

4. Zhang L, Huang X, Li J. Xanthogranuloma of the stomach: a case report. Eur J Surg Oncol 1992;18:293-295.

5. Guarino M, Reale D, Micoli G, Tricomi P, Cristofori E. Xanthogranulomatous gastritis: association with xanthogranulomatous cholecystitis. J Clin Pathol 1993;46:88-90.

6. Lespi PJ. Gastric xanthogranuloma (inflammatory malignant fibrohistiocytoma). Case report and literature review. Acta Gastroenterol Latinoam 1998;28:309-310.

7. Lai HY, Chen JH, Chen CK, et al. Xanthogranulomatous pseudotumor of stomach induced by perforated peptic ulcer mimicking a stromal tumor. Eur Radiol 2006;16:2371-2372.

8. Kubosawa H, Yano K, Oda K, et al. Xanthogranulomatous gastritis with pseudosarcomatous changes. Pathol Int 2007; 57:291-295.

9. Aikawa M, Ishii T, Nonaka K, et al. A case of gastric xanthogranuloma associated with early gastric cancer. Nihon Shokakibyo Gakkai Zasshi 2009;106:1610-1615.

10. Banerjee S, Shah S, Chandran BS, Pulimood A, Mathew G. Chronic perforation in isolated xanthogranulomatous gastritis. Trop Gastroenterol 2010;31:45-47.

11. Kinoshita H, Yamaguchi S, Sakata Y, Arii K, Mori K, Kodama R. A rare case of xanthogranuloma of the stomach masquerading as an advanced stage tumor. World J Surg Oncol 2011;9:67.

12. Tsukada T, Nakano T, Miyata T, Sasaki S, Higashi K. Xanthogranulomatous gastritis mimicking malignant GIST on F-18 FDG PET. Ann Nucl Med 2012;26:752-756.

13. Tajima S, Waki M, Ohata A, Koda K, Maruyama Y. Xanthogranulomatous gastritis associated with actinomycosis: report of a case presenting as a large submucosal mass. Int J Clin Exp Pathol 2015;8:1013-1018.

14. Okamura A, Takahashi T, Saikawa Y, et al. Xanthogranulomatous gastritis of the remnant stomach mimicking a malignant tumor: a case report. Oncol Lett 2016;11:1453-1456.

15. Antonakopoulos GN, Chapple CR, Newman J, et al. Xanthogranulomatous pyelonephritis. A reappraisal and immunohistochemical study. Arch Pathol Lab Med 1988;112:275-281.

16. Hori S, Tsutsumi Y. Helicobacter pylori infection in gastric xanthomas: immunohistochemical analysis of 145 lesions. Pathol Int 1996;46:589-593.

17. Kim EY. Diagnosis of gastric subepithelial tumor: focusing on endoscopic ultrasonography. Korean J Helicobacter Up Gastro- 
intest Res 2015;15:9-16.

18. Lee JH, Lee HL, Ahn YW, et al. Prevalence of gastric subepithelial tumors in Korea: a single center experience. Korean J Gastroenterol 2015;66:274-276.

19. Białek A, Wiechowska-Kozłowska A, Pertkiewicz J, et al. Endoscopic submucosal dissection for treatment of gastric sub- epithelial tumors (with video). Gastrointest Endosc 2012;75: 276-286.

20. Soh JS, Kim JK, Lim H, et al. Comparison of endoscopic submucosal dissection and surgical resection for treating gastric subepithelial tumours. Scand J Gastroenterol 2016;51:633-638. 